\title{
Comparison of acute and late toxicity of two regimens of 3- and 5-week concomitant boost prone IMRT to standard 6-week breast radiotherapy
}

\section{Shahzad Raza ${ }^{1}$, Stella C. Lymberis ${ }^{1}$, Raquel Ciervide ${ }^{1}$, Deborah Axelrod ${ }^{2}$, Maria Fenton-Kerimian ${ }^{1}$, Chiara Magnolfi ${ }^{1}$, Barry Rosenstein ${ }^{1}$, J. Keith DeWyngaert ${ }^{1}$ and Silvia C. Formenti ${ }^{1 *}$}

\footnotetext{
' Department of Radiation Oncology and Surgery, New York University School of Medicine, New York University Langone Medical Center, New York, NY, USA

${ }^{2}$ Department of Surgery, New York University School of Medicine, New York University Langone Medical Center, New York, NY, USA
}

Edited by:

Brian Timothy Collins, Georgetown Hospital, USA

Reviewed by:

Brian Timothy Collins, Georgetown Hospital, USA

Dwight E. Heron, University of

Pittsburgh Cancer Institute, USA

\section{${ }^{*}$ Correspondence:}

Silvia C. Formenti, Department of Radiation Oncology, New York University School of Medicine, 160 East 34th Street, Room 123, New York, New York 10016, USA.

e-mail: silvia.formenti@nyumc.org
Purpose: Limited information is available comparing toxicity of accelerated radiotherapy (RT) to that of standard fractionation RT for early stage breast cancer. We report early and late toxicities of two prone regimens of accelerated intensity-modulated radiation therapy (IMRT) with a concomitant boost (CB) to the tumor bed delivered over 3 or 5 weeks as compared to standard 6 week RT with a sequential electron boost. Methods: From 2/2003 to $12 / 2007,169$ consecutive patients with Stage I-II breast cancer were offered the choice to undergo prone RT with either: a 6-week standard RT regimen of $46 \mathrm{~Gy} / 23$ fractions ( $\mathrm{fx}$ ) to the whole breast (WB), followed by a14 Gy sequential boost (SB) to the tumor bed (6wSB), a 5-week regimen of $50 \mathrm{~Gy}$ to WB with an IMRT CB of $6.25 \mathrm{~Gy}$ in $25 \mathrm{fx}(5 \mathrm{wCB})$; or a 3-week protocol of $40.5 \mathrm{~Gy}$ to WB with an IMRT CB of $7.5 \mathrm{~Gy}$ in $15 \mathrm{fx}$ (3wCB). These regimens were estimated as biologically equivalent, based on alpha/beta $=4$ for tumor control. Toxicities were reported using RTOG and LENT/SOMA scoring. Results: 51/169 patients chose standard $6 \mathrm{WSB}, 28$ selected $5 \mathrm{WCB}$, and 90 enrolled in $3 \mathrm{WCB}$ protocol. Maximum acute toxicity was Grade 3 dermatitis in $4 \%$ of the patients in the $6 \mathrm{wSB}$ compared $1 \%$ in $3 \mathrm{wCB}$. In general, acute complications (breast pain, fatigue, and dermatitis) were significantly less in the $3 w C B$ than in the other schedules $(P<0.05)$. With a median follow-up of 61 months, the only Grade 3 late toxicity was telangiectasia in two patients: one in 3wCB and one in 5wCB group. Notably, fibrosis was comparable among the three groups $(P=N S)$. Conclusion: These preliminary data suggest that accelerated regimens of breast RT over 3 or 5 weeks in the prone position, with an IMRT tumor bed CB, result in comparable late toxicity to standard fractionation with a sequential tumor boost delivered over 6 weeks. As predicted by radiobiological modeling the shorter regimen was associated with less acute effects.

Keywords: breast cancer, radiation therapy, acute and late toxicity

\section{INTRODUCTION}

Management of early breast cancer involves a multimodality approach employing surgery, radiotherapy (RT), chemotherapy, and hormonal therapy, requiring considerable health care resources. For women undergoing breast-conserving surgery, standard fractionation radiotherapy results in excellent cosmesis in most cases (Shafiq et al., 2007), and a recent meta-analysis from 17 randomized trials demonstrates that it produces a $15.7 \%$ reduction in the 10-years risk of any first recurrence and results in a 3.8\% absolute reduction of breast cancer death at 15 years (Darby et al., 2011).

To enhance adherence and reduce costs, strategies have been developed to reduce the overall treatment time and number of visits to the radiation facilities, using accelerated treatment schedules which increase the dose per fraction and/or a concomitant boost (CB) to the tumor bed (Formenti et al., 2007; van der Laan et al., 2007; Jalali et al., 2008).

The general rationale for including a boost to the tumor bed is based on 10 years results of the European Organization for
Research and Treatment of Cancer (EORTC) "boost/no boost" trial that demonstrated a reduction in local recurrence rate when a 16-Gy boost was included ( 6.2 vs. $10.2 \%, P<0.0001$; Poortmans et al., 2008). CB via IMRT improves dose conformality to the breast and boost regions while allowing for the delivery of a larger dose per fraction to the area at high risk of residual microscopic cancer. The concomitant technique shortens the radiotherapy course by $1-3$ weeks while maintaining the biological benefit of a dose increment at the tumor bed site.

Little comparative data with regards to toxicity amongst different fractionation approaches is available for the treatment of breast cancer, particularly in the prone position. To our knowledge, no prospective randomized studies have compared daily radiotherapy over 3 or 5 weeks with a $\mathrm{CB}$ to the tumor bed to the standard 6 weeks regimen that includes a consecutive boost.

We identified in our database a consecutive group of patients who had undergone breast-conservation surgery and who, at initial consultation for post-operative radiotherapy, were offered, based on their tumor characteristics, to choose among three 
approaches: standard 6 week radiation therapy with a sequential boost $(6 \mathrm{wSB})$, a regimen of 5 weeks of daily radiotherapy with a $\mathrm{CB}$ using IMRT $(5 \mathrm{wCB})$ or a protocol of 3 weeks daily radiotherapy with a $\mathrm{CB}$ using IMRT ( $3 \mathrm{wCB})$, respectively. Each patient was first offered standard therapy and then informed about the two accelerated regimens. Patient's preference dictated the choice of treatment, as documented in the medical record. We compare acute and late toxicity outcomes for patients treated on the three regimens.

\section{MATERIALS AND METHODS STUDY DESIGN AND ELIGIBILITY}

The study was approved by the NYU Institutional Review Board and the collection, storage, and retrieval of data were all done in compliance with the Health Insurance Privacy and Portability Act. The consecutive cohort was defined as Stage I-II breast cancer patients who, after segmental mastectomy with negative margins, were offered the choice to undergo whole breast radiotherapy either with a standard fractionation regimen of 6 weeks that included a sequential boost (SB) to the tumor bed or with a hypo-fractionation regimen of 3 or 5 weeks with IMRT to deliver a CB to the tumor bed. Patients were identified from the departmental record and verify databases (ARIA, Varian Medical System, Palo, Alto, CA, USA).

A total of 169 consecutive patients with the above characteristics were identified. In 159/169 patients a documented follow up visit, at least a year after completing radiotherapy was available for evaluation of late effects.

\section{RADIOBIOLOGIC RATIONALE FOR DOSE AND FRACTIONATION SCHEDULE}

The 6-week schedule (6wSB) prescribed 60 Gy in 30 fractions of 2 Gy over 6 weeks: the first 23 fractions targeting the whole breast prone, followed by the remaining 7 fractions targeting the tumor bed with an electron boost field, set-up in supine position. The 5week CB schedule (5wCB) delivered 50 Gy in 25 fractions of 2 Gy to the prone breast, with a daily $\mathrm{CB}$ of $25 \mathrm{cGy}$ to the tumor bed, over a total of 5 weeks. Finally, the 3 week $\mathrm{CB}$ schedule ( $3 \mathrm{wCB}$ ) delivered a total dose of $40.5 \mathrm{~Gy}$, at $2.7 \mathrm{~Gy}$ in 15 fractions to the prone breast with an additional $\mathrm{CB}$ of $0.5 \mathrm{~Gy}$ delivered to the tumor bed, for a total dose of $48 \mathrm{~Gy}$ to the lumpectomy site. The results of the latter regimen were previously reported (DeWyngaert et al., 2007; Formenti et al., 2007).

The linear-quadratic model (Fowler, 1989) was used to determine whether the proposed accelerated intensity-modulated RT (AIMRT) protocol yields a roughly equal probability of tumor control compared with a standard schedule, using a tumor $\alpha / \beta$ of 4 . This is the same $\alpha / \beta$ value that Owen et al. (2006) derived based on UK National Cancer Research Institute (NCRI) randomized trial which evaluated three dose schedules for breast cancer treatment. BEDs for the standard and accelerated IMRT schedules were calculated, as previously described (DeWyngaert et al., 2007), assuming that full repair takes place during the $\geq 24$-h interval between fractions.

Table 1 lists the BEDs for tumor control, early responses to radiation effects (erythema and desquamation), and late responses (telangiectasia and fibrosis) for the three fractionation schedules. The choices for the $\alpha / \beta$ values used for these computations have
Table 1 | Biologically equivalent doses for late effects and tumor control.

\begin{tabular}{|c|c|c|c|c|}
\hline & \multirow[t]{3}{*}{$\alpha / \beta(\mathrm{Gy})$} & $6 W S B$ & \multirow{2}{*}{$\begin{array}{l}5 w C B \\
\text { Schedule }^{\dagger} \\
2 \mathrm{~Gy} \times 25\end{array}$} & \multirow{2}{*}{$\begin{array}{l}\text { 3wCB } \\
\text { Schedule }^{\dagger \dagger} \\
2.7 \mathrm{~Gy} \times 15\end{array}$} \\
\hline & & $\begin{array}{l}\text { Schedule* } \\
2 \mathrm{~Gy} \times 23\end{array}$ & & \\
\hline & & in 39 days & in 32 days & in 18 days \\
\hline \multicolumn{5}{|c|}{ LATE EFFECTS } \\
\hline Fibrosis & 2 & $92 \mathrm{~Gy}_{2}$ & $100 \mathrm{~Gy}_{2}$ & $95 \mathrm{~Gy}_{2}$ \\
\hline Telangiectasia & 4 & $69 \mathrm{~Gy}_{4}$ & $75 \mathrm{~Gy}_{4}$ & $68 \mathrm{~Gy}_{4}$ \\
\hline Erythema & 8 & $58 \mathrm{~Gy}_{8}$ & $63 \mathrm{~Gy}_{8}$ & $54 \mathrm{~Gy}_{8}$ \\
\hline \multirow[t]{4}{*}{ Desquamation } & 11 & $54 \mathrm{~Gy}_{11}$ & $59 \mathrm{~Gy}_{11}$ & $50 \mathrm{~Gy}_{11}$ \\
\hline & $\alpha / \beta(\mathrm{Gy})$ & 6WSB & $5 w C B$ & $3 w C B$ \\
\hline & & $\begin{array}{l}\text { Schedule } \\
2 \mathrm{~Gy} \times 23\end{array}$ & $\begin{array}{l}\text { Schedule } \\
2 \mathrm{~Gy} \times 25\end{array}$ & $\begin{array}{l}\text { Schedule } \\
3.2 \mathrm{~Gy} \times 15\end{array}$ \\
\hline & & in 39 days & in 32 days & in 18 days \\
\hline \multicolumn{5}{|c|}{ TUMOR CONTROL } \\
\hline Tumor & 2 & $120 \mathrm{~Gy}_{2}$ & $120 \mathrm{~Gy}_{2}$ & $125 \mathrm{~Gy}_{2}$ \\
\hline Tumor§ & 2 & $116 \mathrm{~Gy}_{2}$ & $118 \mathrm{~Gy}_{2}$ & $125 \mathrm{~Gy}_{2}$ \\
\hline Tumor & 4 & $90 \mathrm{~Gy}_{4}$ & $88 \mathrm{~Gy}_{4}$ & $86 \mathrm{~Gy}_{4}$ \\
\hline Tumor§ & 4 & $86 \mathrm{~Gy}_{4}$ & $86 \mathrm{~Gy}_{4}$ & $86 \mathrm{~Gy}_{4}$ \\
\hline Tumor & 10 & $72 \mathrm{~Gy}_{10}$ & $69 \mathrm{~Gy}_{10}$ & $63 \mathrm{~Gy}_{10}$ \\
\hline Tumor§ & 10 & $68 \mathrm{~Gy}_{10}$ & $67 \mathrm{~Gy}_{10}$ & $63 \mathrm{~Gy}_{10}$ \\
\hline
\end{tabular}

${ }^{*} 6 w S B, 6-W e e k$ sequential boost; ${ }^{+} 5 w C B, 5$-week concomitant boost; ${ }^{+t} 3 w C B$, 3-week concomitant boost; $\S$, taking into account cell proliferation during the course of treatment.

been justified in previous studies (Steel et al., 1987; Matthews et al., 1989; Turesson and Thames, 1989; Thames et al., 1990; Archambeau et al., 1995; Yamada et al., 1999).

Both hypo-fractionated schedules are also accelerated protocols in which the total dose is delivered in 32 or 18 days vs. the standard schedule delivered over 39 days. Accounting for tumor proliferation that will take place during the additional treatment (Travis and Tucker, 1987; Fowler, 1989; Stanton et al., 1996; Haustermans et al., 1998) as presented in Table 1, the inclusion of a cell proliferation correction factor produces small decreases in the BEDs for the standard treatment. Therefore, taking into consideration tumor proliferation during treatment, an alpha/beta of 4 corresponds to equivalent tumor control probability among the three schedules.

The BED calculations for the $5 \mathrm{wCB}$ schedule estimate a slightly higher rate of early effects, erythema and desquamation and of late telangiectasia and fibrosis as compared with the standard fractionation schedule. Conversely, the BED calculations of the $3 \mathrm{wCB}$ schedule estimate a lower rate of acute effects of erythema, desquamation, and comparable late effects to those of standard fractionation.

PRONE PATIENT SET-UP AND COMPUTED TOMOGRAPHY SIMULATION All patients were placed in the prone position on a dedicated treatment platform for computed tomography (CT) planning and treatment. The platform, placed on top of the CT couch, contains an open aperture on one side to allow for the index breast to fall away from the chest wall. Before the patients lay down prone on the platform for CT scanning, they were positioned supine and a radiation oncologist placed fiducial markers on their 
skin to clinically define the medial, lateral, caudal, and cephalad breast field borders. Subsequently, non-contrast CT images were acquired at $2.5-3.75 \mathrm{~mm}$-thick intervals, from the level of the mandible to below the diaphragm. Details on the NYU prone technique were previously reported (Huppert et al., 2011).

\section{TREATMENT PLANNING FOR THE STANDARD 6-WEEK RT SCHEDULE}

The standard schedule consisted of a 2-Gy daily fraction delivered 5 days a week to a dose of 46 Gy to the whole breast, followed by a SB to the lumpectomy cavity treated either supine with en-face electrons or, less frequently, prone using photon tangents fields prone. Field definition to treat the entire breast was based on the following: opposed tangent photon beams were used to treat the entire breast tissue as identified at CT, in the prone position from midline and with the posterior edge of the field extending to the anterior edge of the latissimus dorsi muscle laterally.

The prone whole breast plans were created with two, three, or four fields using a field in-field technique and enhanced dynamic wedges as necessary using 3D-CRT planning. The boost target volume was contoured using evidence of the persisting surgical cavity at CT simulation and/or based on review of original patient records including mammography, ultrasound, magnetic resonance imaging, and operative records.

\section{TREATMENT PLANNING FOR CONCOMITANT BOOST SCHEDULES (5wCB AND 3wCB DEFINITION OF PLANNING TARGET VOLUMES)}

Patients in the 5-and 3-week CB regimen were treated in the prone position using $6 \mathrm{MV}$ photons using the technique of CB IMRT previously described (DeWyngaert et al., 2007). Patients in the 5-week schedule were treated with 50 Gy in 25 daily fractions of 2 Gy to the whole breast (PTV1) prescribed to the $100 \%$ isodose line with the tumor bed region (PTV2) boosted daily by an additional $0.25 \mathrm{~Gy}$, using IMRT (total boost dose $6.25 \mathrm{~Gy}$ ). For patients in the $3 \mathrm{wCB}$ protocol the whole breast (PTV1) was treated to a daily fraction dose of 2.7 Gy, with the tumor bed region (PTV2) boosted by an additional $0.5 \mathrm{~Gy}$, using IMRT (total boost dose $7.5 \mathrm{~Gy}$ ).

Separate non-coplanar IMRT fields were specifically designed to deliver the boost dose to the lumpectomy site on top of the ipsilateral whole breast dose planned using conventional 3D conformal techniques (Formenti et al., 2007). In the majority of patients, a two field IMRT field approach similar to mini-tangent non-coplanar beam arrangement was used to target the tumor bed. The whole breast plans were created using two or three fields, with enhanced dynamic wedges as necessary. These plans were used as a base plan for optimization of the boost fields. The optimization and calculations were done using Eclipse software (Varian Medical Systems, Palo Alto, CA, USA) using gradient-dependent optimization algorithm to satisfy dose-volume objectives and constraints for PTV1, PTV2, body, lung, and heart. The goals of planning were to deliver a $\mathrm{CB}$ to the tumor bed and to minimize the size of the hot spot volumes outside of PTV2. Planning constraints limited $5 \%$ of the heart volume to receive $18 \mathrm{~Gy}$ and $10 \%$ of the ipsilateral lung volume to receive less than $20 \mathrm{~Gy}$.

\section{ASSESSMENT OF TOXICITIES}

Acute skin toxicity was assessed by the treating radiation oncologist as a part of the standard weekly assessment, during radiation treatment, with the maximum toxicity scored during and within
90 days of radiation. Individual indices for acute skin toxicity like faint erythema, bright or brisk erythema, dry desquamation, and wet desquamation were noted. Late toxicity was assessed at least a year after radiotherapy and then yearly thereafter. For late skin toxicities, asymmetry, edema, telangiectasia, induration, hyperpigmentation, and fibrosis were recorded. The reported toxicities score represents the maximal point of toxicity assigned during and after the radiation treatment or reported by the patient during and after RT completion.

Toxicities were scored according to the Radiation Therapy Oncology Group (RTOG)/the EORTC toxicity scale associated with radiation, and the late effects of normal tissue-subjective objective management analytical (LENT/SOMA) scale (Hoeller et al., 2003) for delayed toxicities as shown in Table 2.

\section{STATISTICAL METHODS}

Patient and disease characteristics were compared using pair-wise comparisons among the $3 \mathrm{wCB}, 5 \mathrm{wCB}$, and $6 \mathrm{wSB}$ schedules using the Fischer's exact test using the SAS statistical software program. Pair-wise comparisons using Fischer's exact test were also performed to compare the three schedules with regard to acute and late toxicities.

\section{RESULTS}

From February 2003 to January 2005, 51 patients selected the standard $6 \mathrm{wSB}, 28$ patients the $5 \mathrm{wCB}$ and 90 patients the $3 \mathrm{wCB}$ regimen. Patient characteristics are described in Table 3 that includes the results of pair-wise comparisons between the schedules, calculated by the Fisher's exact test using the SAS statistical software program.

The patient and treatment characteristics were similar among the three groups regarding age (median 52, 54, and 57 for the standard, $5 \mathrm{wCB}$ and $3 \mathrm{wCB}$ groups, respectively), KPS, tumor and nodal staging, and histology. There were more white and fewer Hispanic patients treated with the $3 \mathrm{wCB}$ than the $5 \mathrm{wCB}$ schedule, $P=0.021$ and $P=0.018$, respectively. There were significantly less patients with estrogen receptor positive status in the $5 \mathrm{wCB}$ group than in the other groups $(P<0.05)$, and significantly more HER2/NEU negative patients in the $3 \mathrm{wCB}$ cohort than in the other two groups $(P<0.05)$. More patients in the $3 \mathrm{wCB}$ group received anti-hormone therapy as compared with both the $5 \mathrm{wCB}$ and $6 \mathrm{wSB}$ schedules $(P<0.05)$. Finally, about the same ratio of patients in all three groups received chemotherapy $(P=\mathrm{NS})$, in most cases consisting of a combination of doxorubicin, cyclophosphamide, and paclitaxel.

\section{ACUTE TOXICITY}

None of the patients underwent treatment breaks because of acute toxicity. Table 4 describes the incidence of acute toxicity during radiation therapy, consisting mainly of radiation dermatitis. Specifically, Grade 1 radiation dermatitis was observed in $27 \%$ of the recipients of $6 \mathrm{wSB}, 27 \%$ of $5 \mathrm{wCB}$, and $58.5 \%$ of $3 \mathrm{wCB}$. Grade 2 dermatitis was seen in $68.6 \%$ of patients on $6 \mathrm{wSB}, 73 \%$ of patients on $5 \mathrm{wCB}$, and $8.1 \%$ of patients on $3 \mathrm{wCB}$ regimen. Grade 3 skin reactions were noted in 2 patients $(4 \%)$ from $6 \mathrm{wSB}$ vs. one $(0.9 \%)$ in the $3 \mathrm{wCB}$ regimen and in none of those treated with the $5 \mathrm{wCB}$ regimen. Figure 1 demonstrates a patient who was treated with the 6-week standard fractionation regiment exhibiting Grade 2 brisk erythema at the end of treatment. 
Table 2 | Scoring for acute and late toxicities.

\section{A. Acute radiation dermatitis}

\begin{tabular}{|c|c|c|c|c|}
\hline & \multicolumn{4}{|c|}{ Common terminology criteria for radiation dermatitis } \\
\hline 1 & \multicolumn{4}{|c|}{ Faint erythema or dry desquamation } \\
\hline 2 & \multicolumn{4}{|c|}{ Moderate to brisk erythema; patchy moist desquamation, mostly confined to skin folds and creases; moderate edema } \\
\hline 4 & \multicolumn{4}{|c|}{ Skin necrosis or ulceration of full thickness dermis; spontaneous bleeding from involved site } \\
\hline 5 & \multicolumn{4}{|l|}{ Death } \\
\hline & Grade 1 & Grade 2 & Grade 3 & Grade 4 \\
\hline \multicolumn{5}{|l|}{ RTOG/EORTC } \\
\hline Skin & $\begin{array}{l}\text { Slight atrophy, pigmentation } \\
\text { change, some hair loss }\end{array}$ & $\begin{array}{l}\text { Patchy atrophy, moderate } \\
\text { telangiectasia, total hair loss }\end{array}$ & $\begin{array}{l}\text { Marked atrophy, gross } \\
\text { telangiectasia }\end{array}$ & Ulceration \\
\hline Pain & $\begin{array}{l}\text { Occasional and minimal } \\
\text { hypersensation, pruritus }\end{array}$ & Intermittent and tolerable & Persistent and intense & $\begin{array}{l}\text { Refractory, } \\
\text { excruciating }\end{array}$ \\
\hline \multicolumn{5}{|c|}{ LENT/SOMA - BREAST OBJECTIVE } \\
\hline Telangiectasia & $<1 \mathrm{~cm}^{2}$ & $1-4 \mathrm{~cm}^{2}$ & $>4 \mathrm{~cm}^{2}$ & \\
\hline Fibrosis & $\begin{array}{l}\text { Barely palpable, increased } \\
\text { density }\end{array}$ & $\begin{array}{l}\text { Definite increased intensity and } \\
\text { firmness }\end{array}$ & $\begin{array}{l}\text { Very marked density, retraction, and } \\
\text { fixation }\end{array}$ & \\
\hline Edema & Asymptomatic & Symptomatic & Secondary dysfunction & \\
\hline Retraction, atrophy & $10-25 \%$ & $>25-40 \%$ & $>40-75 \%$ & Whole breast \\
\hline \multicolumn{5}{|l|}{ LENT/SOMA - SKIN } \\
\hline Pigmentation change & Transitory, slight & Permanent, marked & - & - \\
\hline
\end{tabular}

RTOG, Radiation Therapy Oncology Group; EORT, European Organization for Research and Treatment of Cancer; LENT/SOMA, late effects of normal tissue task force; SOMA, subjective, objective, management and analytic.

*Hoeller et al. (2003).

Pair-wise comparisons of acute complications with $P$-values less than 0.05 were chosen to detect when the data differed significantly in the $5 \mathrm{wCB}$ vs. $6 \mathrm{wSB}, 5 \mathrm{wCB}$ vs. $3 \mathrm{wCB}$, and $6 \mathrm{wSB}$ vs. $3 \mathrm{wCB}$ schedules (Fisher's exact test, SAS statistical software program). All acute complications including breast pain, fatigue, and dermatitis were significantly less frequent among the patients in the $3 \mathrm{wCB}$ than in either the $5 \mathrm{wCB}$ or $6 \mathrm{wSB}$ schedule $(P<0.05)$. Breast edema occurred less frequently among patients treated with the 3 -week compared to the $5 \mathrm{wCB}$ schedule $(P=0.004)$, but not significantly less compared to the 6-week schedule $(P=0.081)$.

Figure 2 describes the maximum incidence of acute skin toxicity among the three treatment groups: the $6 \mathrm{wSB}$ was associated with increased incidence of acute skin toxicity as compared with either the $3 \mathrm{wCB}$ or $5 \mathrm{wCB}$ schedules. The latter two had comparable patterns.

All patients in the $6 \mathrm{wSB}$ and $5 \mathrm{wCB}$ schedule and most in the $3 \mathrm{wCB}$ developed Grade 1 dermatitis. As shown in Figure 3, at week 3 about $70 \%$ of patients on the $6 \mathrm{wSB}$ and $5 \mathrm{wCB}$ schedule developed Grade 2 dermatitis, while only $11 \%$ of patients on the $3 \mathrm{wCB}$ protocol. Also, Grade 3 dermatitis at the end of treatment occurred in $4 \%$ of patients on the $6 \mathrm{wSB}$ and $1 \%$ of patients on the $3 \mathrm{wCB}$ at the end of treatment.

Pain and fatigue were also more often experienced among recipients of the $6 \mathrm{wSB}$ regimen, with three patients experiencing Grade 3 pain. Twenty-five patients (49\%) reported pain during $6 \mathrm{wSB}$ regimen compared to only eight patients $(28.5 \%)$ in $5 \mathrm{wCB}$ and $1(0.9 \%)$ in $3 \mathrm{wCB}$ group $(P<0.05)$. Fatigue was also more pronounced among recipients of $6 \mathrm{wSB}: 15.7 \%$ compared to $10.7 \%$ in the $5 \mathrm{wCB}$ and $0.9 \%$ in $3 \mathrm{wCB}$ group $(P<0.05$ for $3 \mathrm{wCB}$ as compared to $5 \mathrm{wCB}$ and $6 \mathrm{wSB})$. Patients in the $5 \mathrm{wCB}$ schedule exhibited more edema (43\%) compared to $6 \mathrm{wSB}(29.4 \%)$ and $3 \mathrm{wCB}$ schedule (15.5\%), with statistically significant increased edema seen for patients treated with $5 \mathrm{wCB}$ as compared with $3 \mathrm{wCB}(P<0.05)$.

\section{LATE TOXICITIES}

Late toxicities are listed in Table 5 with a median follow up of 61 months. A statistically significant difference in late grade $\geq 1$ asymmetry was noted comparing the $3 \mathrm{wCB}$ and $5 \mathrm{wCB}$ schedule with conventional $6 \mathrm{wSB}$, with reduced asymmetry noted in both accelerated schedules $(P<0.05)$. 
Table 3 | Distribution of baseline patient and tumor characteristics among the three groups of patients.

\begin{tabular}{|c|c|c|c|c|c|c|}
\hline Demographics & $\begin{array}{l}\text { Standard 6wSB* } \\
(N=51)\end{array}$ & $\begin{array}{l}\text { AIMRT 5wCB }{ }^{\dagger} \\
(N=28)\end{array}$ & $\begin{array}{l}\text { AIMRT 3wCB }{ }^{\dagger \dagger} \\
(N=90)\end{array}$ & $5 w C B$ vs. $6 w S B * *$ & $3 w C B$ vs. $5 w C B * *$ & $3 w C B$ vs. $6 w S B * *$ \\
\hline \multicolumn{7}{|l|}{ TUMOR STAGE I } \\
\hline $\mathrm{T} 1 \mathrm{~b}$ & 45 & 23 & 82 & 0.76 & 0.587 & 1 \\
\hline T1c & 35 & 19 & 63 & 0.815 & 0.829 & 1 \\
\hline \multicolumn{7}{|l|}{ TUMOR STAGE II } \\
\hline \multicolumn{7}{|l|}{ NODAL STAGE } \\
\hline Negative & 40 & 26 & 72 & 0.122 & 0.1526 & 0.8312 \\
\hline Positive & 11 & 2 & 18 & & & \\
\hline \multicolumn{7}{|l|}{ HISTOLOGY } \\
\hline Ductal carcinoma & 50 & 25 & 79 & 0.125 & 1 & 0.0557 \\
\hline Lobular carcinoma & 0 & 2 & 7 & 0.123 & 1 & 0.0487 \\
\hline Black & 5 & 1 & 6 & 0.415 & 1 & 0.5266 \\
\hline Hispanic & 6 & 5 & 3 & 0.507 & 0.018 & 0.0715 \\
\hline Asian & 2 & 2 & 2 & 0.34 & 0.0861 & 0.6202 \\
\hline \multicolumn{7}{|c|}{ TUMOR ESTROGEN RECEPTOR STATUS } \\
\hline Negative & 10 & 14 & 16 & 0.01 & 0.0012 & 0.8233 \\
\hline Positive & 41 & 14 & 74 & & & \\
\hline \multicolumn{7}{|c|}{ TUMOR PROGESTERONE RECEPTOR STATUS } \\
\hline Negative & 19 & 20 & 37 & 0.005 & 0.0086 & 0.7217 \\
\hline Positive & 32 & 8 & 53 & & & \\
\hline \multicolumn{7}{|c|}{ TUMOR HER2/NEU STATUS } \\
\hline Negative & 40 & 21 & 85 & 0.783 & 0.0071 & 0.0058 \\
\hline
\end{tabular}

${ }^{*} 6 w S B, 6$-week sequential boost; ${ }^{+} 5 w C B, 5$-week concomitant boost; ${ }^{+\dagger} 3 w C B, 3-w e e k$ concomitant boost; ${ }^{*}$ Pair-wise comparisons were made between the 5 wCB, $6 w S B$, and $3 w C B$ schedules, using the Fischer's exact test.

Late complications of telangiectasia, skin pigmentation, and fibrosis at 5 years were comparable among the three groups $(P=\mathrm{NS})$. Grade III telangiectasia occurred in 1 patient treated by the $3 \mathrm{wCB}$ and in 1 patient in the $5 \mathrm{wCB}$ protocol.

Finally, $14 \%$ of patients treated with $6 \mathrm{wSB}$ regimen, $10 \%$ with the $5 \mathrm{wCB}$ and $25.8 \%$ of patients on $3 \mathrm{wCB}$ developed Grade 1 hyper-pigmentation changes: only one patient $(0.6 \%)$ in the $6 \mathrm{wSB}$ developed Grade 2 hyper-pigmentation. Grade 1 fibrosis, defined as a barely palpable increased density compared to the other breast, was noted in $7 \%$ in the $6 \mathrm{wSB}, 2.5 \%$ in the $5 \mathrm{wCB}$, and $19 \%$ in the $3 \mathrm{wCB}$ regimen. Grade 2 fibrosis was less common with the $6 \mathrm{wSB}$ $(1.2 \%)$ and $5 \mathrm{wCB}(0.6 \%)$ compared to $3 \mathrm{wCB}$ regimen $(5 \%)$.

\section{DISCUSSION}

Standard radiation dose fractionation for the treatment of early stage breast cancer has two main shortcomings: the inconvenience to patients who attend daily treatment for 6-7 weeks and the cost associated with a prolonged usage of the facilities. Among the strategies that have been employed to reduce the treatment time, the Canadian trial by Whelan et al. $(2002,2010)$ has generated solid evidence in favor of a hypo-fractionated, accelerated, whole breast irradiation for selected women with early stage breast cancer. However, at a non-planned subset analysis the hypo-fractionated regimen appeared to be less effective in patients with high-grade tumors, and it was associated at 10 years median follow up with a cumulative incidence of local recurrence of $15.6 \%$ compared to $4.7 \%$ among similar patients assigned to the standard fractionation group $(P=0.01$; Smith et al., 2009).

Croog et al. reported the results in a consecutive series of 128 patients treated with a prone IMRT approach consisting of 16 daily fractions of $265 \mathrm{cGy}$ to a total dose of $4,240 \mathrm{cGy}$ 
Table 4 | Comparison of acute radiation toxicity among the three regimens.

\begin{tabular}{|c|c|c|c|c|c|c|}
\hline & $6 \mathrm{wSB} * N=51$ & ${ }^{5 w C B}{ }^{\dagger} N=28$ & $3 \mathrm{wCB}^{\dagger \dagger} N=90$ & $5 w C B$ vs. $6 w S B * *$ & $3 w C B$ vs. $5 w C B * *$ & $3 w C B$ vs. $6 w S B * *$ \\
\hline \multicolumn{7}{|c|}{ BREAST PAIN } \\
\hline Grade 1 & 25 & 8 & 1 & 0.098 & $3.21-05$ & $1.40-12$ \\
\hline Grade 3 & 3 & 0 & 0 & 0.549 & N/A & 0.0455 \\
\hline \multicolumn{7}{|c|}{ FATIGUE } \\
\hline \multicolumn{7}{|c|}{ RADIATION DERMATITIS } \\
\hline Grade 1 & 51 & 28 & 75 & N/A & 0.0204 & 0.0011 \\
\hline Grade 2 & 37 & 20 & 10 & 1 & $1.96-09$ & $1.15-13$ \\
\hline Grade 3 & 2 & 0 & 1 & 0.537 & 1 & 0.2965 \\
\hline \multicolumn{7}{|c|}{ BREAST EDEMA } \\
\hline
\end{tabular}

${ }^{*} 6 w S B, 6$-week sequential boost; ${ }^{\dagger} 5 w C B, 5$-week concomitant boost; ${ }^{+\dagger} 3 w C B, 3-w e e k$ concomitant boost. ${ }^{*}$ Pair-wise comparisons were made between the $5 w C B$, $6 W S B$, and $3 w C B$ schedules, using the Fischer's exact test.

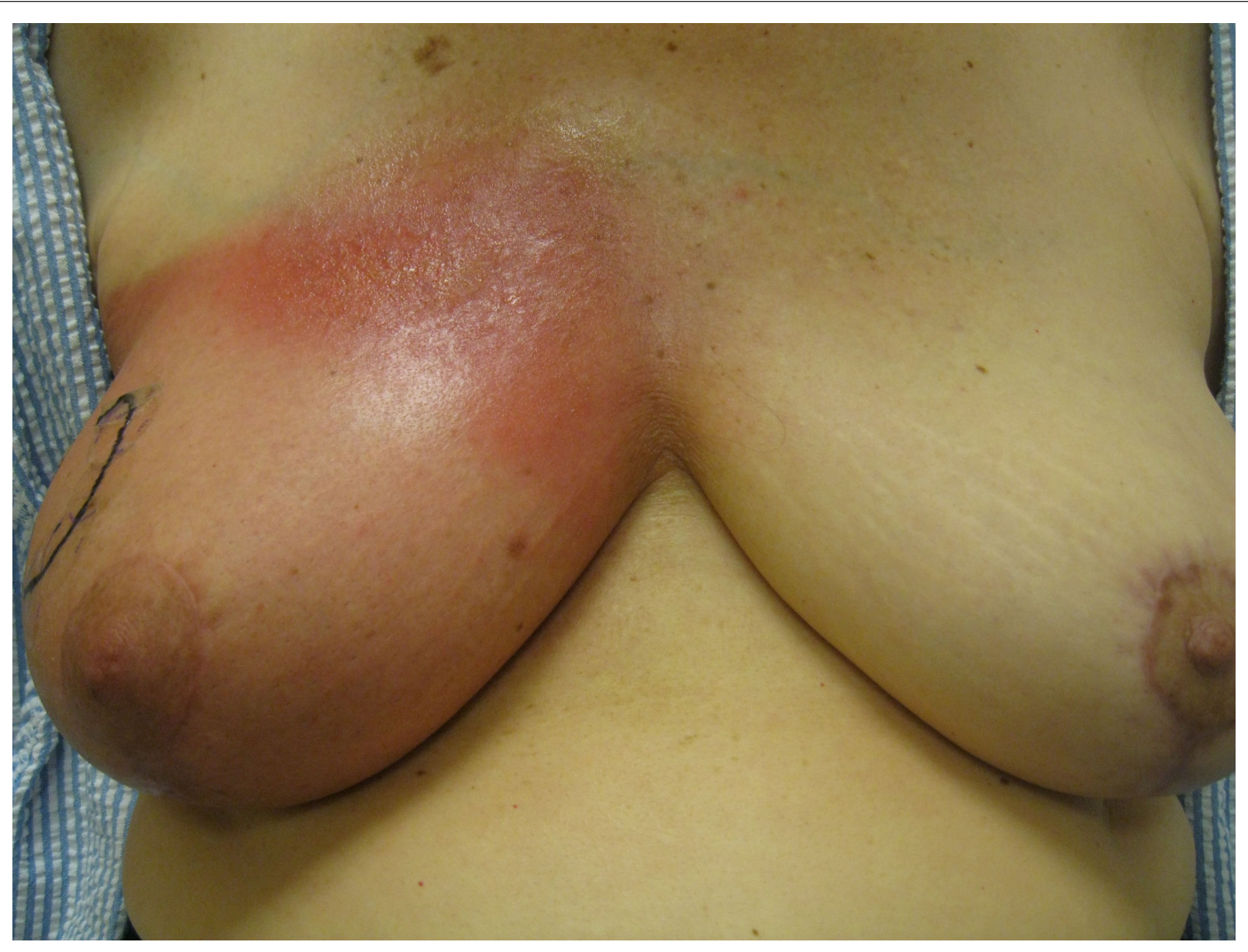

FIGURE 1 | Example of a patient treated with the 6wSB regimen demonstrating Grade 2 erythema during the final week of treatment, while receiving the sequential boost to the upper outer quadrant.

followed by a conventionally fractionated boost, over 29 days. At a median follow-up of 18 months, one ipsilateral breast recurrence developed that was salvaged with mastectomy and immediate reconstruction (Croog et al., 2009).
Since 2003, we developed a series of research protocols testing feasibility and safety of a CB to the tumor bed, delivered by IMRT. Results from randomized trials have suggested that both local control of breast cancer and late change in breast appearance 


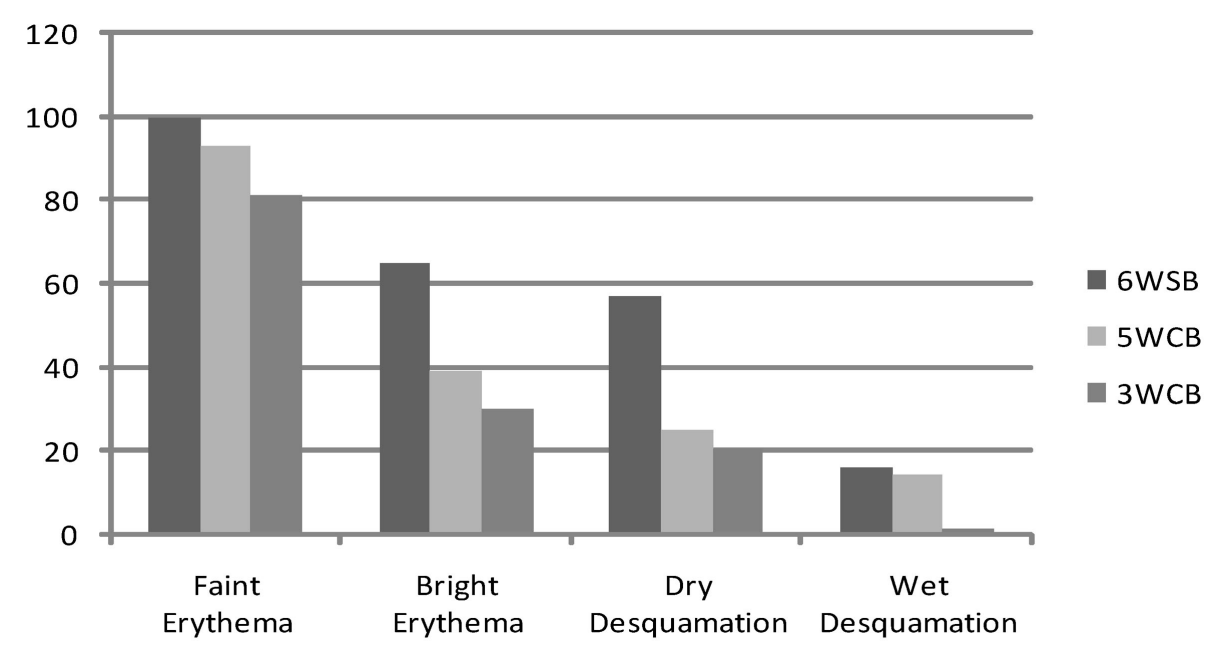

FIGURE 2 |Acute toxicities: maximum incidence of erythema and desquamation between the three regimens: $6 \mathrm{wSB}$ (6-week sequential boost), 5wC (5-week concomitant boost), and 3wCB (3-week concomitant boost).

FIGURE 3 | Kinetics of Grade 2 and 3 acute toxicities. Grade 2 toxicity (brisk erythema) was noticed at week 3 in $70 \%$ of patients in $5 \mathrm{wCB}$ and $6 \mathrm{wSB}$ schedules and in only $11 \%$ of the patients treated with $3 w C B$. Grade 3 dermatitis was seen in $1 \%$ of patients in the $3 \mathrm{wCB}$ and $4 \%$ of patients on the $6 \mathrm{wSB}$ schedule at 3 and 6 weeks, respectively. exhibit similar sensitivity to fraction size as modeled by the $\alpha / \beta$ ratio in the linear-quadratic formulation (Bentzen et al., 2008). Based on radiobiological modeling, we selected regimens that would provide biological effective dose equivalence to that of standard 6-conventional fractionation to $60 \mathrm{~Gy}$ using an $\alpha / \beta$ value of 4 for tumor control, and taking into consideration the different repopulation with a shorter, accelerated regimen (Rosenstein et al., 2004). Although BED modeling calculations for the $5 \mathrm{wCB}$ schedule estimated a slightly higher rate of early effects, erythema and desquamation and of late telangiectasia and fibrosis as compared with the standard fractionation schedule, this was not observed in this consecutive series of patients. In contrast, BED calculations of the $3 \mathrm{wCB}$ schedule estimated a lower rate of acute effects of erythema, desquamation, and a slight increase in fibrosis compared to conventional fractionation, as observed in the patients included in this report.

Other centers have also pilot-tested a CB accelerated fractionation regimen. At Fox Chase, 75 patients were treated with a hypo-fractionated regiment of IMRT in 20 treatments of $2.25 \mathrm{~Gy}$ per day for a total of 45 Gy over 4 weeks (Freedman et al., 2007). An electron boost was added, bringing dose to $2.8 \mathrm{~Gy}$ per fraction for a total of $56 \mathrm{~Gy}$ to the original tumor bed. Acute toxicity 
Table 5 | Comparison of late toxicity among the three regimens, at 5-year median follow-up ( $N=159$ patients).

\begin{tabular}{|c|c|c|c|c|c|c|}
\hline & $6 w S B * N=46$ & $5 w \mathrm{wB}^{\dagger} N=23$ & $3 w C B^{\dagger \dagger} N=90$ & $5 w C B$ vs. $6 w S B * *$ & $3 w C B$ vs. $5 w C B * *$ & $3 w C B$ vs. $6 w S B * *$ \\
\hline \multicolumn{7}{|c|}{ ASYMMETRY } \\
\hline Grade 1 & 41 & 14 & 61 & 0.01 & 0.622 & 0.007 \\
\hline \multicolumn{7}{|c|}{ PALPABLE MASS } \\
\hline Grade 1 & 3 & 0 & 11 & 0.546 & 0.116 & 0.382 \\
\hline Grade 1 & 26 & 12 & 61 & 0.8 & 0.222 & 0.257 \\
\hline Grade 2 & 3 & 0 & 9 & 0.546 & 0.2 & 0.751 \\
\hline \multicolumn{7}{|c|}{ FIBROSIS } \\
\hline Grade 1 & 14 & 5 & 38 & 0.572 & 0.093 & 0.197 \\
\hline Grade 2 & 2 & 1 & 8 & 1 & 0.683 & 0.494 \\
\hline \multicolumn{7}{|c|}{ TELANGIECTASIA } \\
\hline \multicolumn{7}{|c|}{ HYPER-PIGMENTATION } \\
\hline Grade 1 & 24 & 16 & 41 & 0.203 & 0.06 & 0.475 \\
\hline Grade 2 & 1 & 0 & 0 & 1 & N/A & 0.338 \\
\hline
\end{tabular}

${ }^{*} 6 w S B, 6$-week sequential boost; ${ }^{\dagger} 5 w C B, 5$-week concomitant boost; ${ }^{\dagger \dagger} 3 w C B, 3$-week concomitant boost. ${ }^{* *}$ Pair-wise comparisons were made between the $5 w C B$, $6 w S B$, and $3 w C B$ schedules, using the Fischer's exact test.

was tolerable with the majority of patients experiencing only Grade 1 skin toxicity. Late toxicity was not reported nor were the results compared to those obtained at the same institution when a standard fractionation regimen was utilized.

We previously reported the results of the $3 \mathrm{wCB}$ trial (Formenti et al., 2007), but no prospective comparison of the morbidity associated with different fractionation regimens utilizing a boost is available. While evidence to this regard would be best generated by a prospective randomized trial comparing the different fractionation regimens, the analysis of a consecutive cohort of patients with comparable characteristics and tumors, treated at the same institution, self-allocated to either of the three regimens can provide some initial information. The present analysis demonstrates reassuring preliminary data that late toxicity at 5 years of the $3 \mathrm{wCB}$ schedule is likely to be at least comparable, and acute toxicity appears to be less.

A 2010 Cochrane Collaboration Intervention Review (James et al., 2010) addressed the effects of altered fractionation size on women with early breast cancer who have undergone breast conservation surgery. Four randomized trials reported on 7095 women with node negative breast cancer, negative margin of surgical resection and tumors measuring less than $3 \mathrm{~cm}$ in diameter $(89.8 \%)$. The results of this analysis demonstrated that compared to standard fractionation regimens, accelerated, hypo-fractionated radiation therapy ( $>2$ Gy per fraction) does not adversely affect the local recurrence risk ratio (RR 0.97, $P=0.78$ ), breast appearance (RR 1.17, $P=0.09$ ), or 5-year survival (RR $0.89, P=0.16$ ). Acute skin toxicity was found to be decreased with hypo-fractionation compared to standard fractionation (RR $0.21, P=0.007$ ). Many patients in the randomized trials included in the meta-analysis received a SB, after completing either hypo-fractionated or standard radiation. However, none of the studies analyzed compared a concurrent boost to a sequential one, as compared in this report.

Finally, current guidelines on the use of hypo-fractionated treatment tend to exclude patients who receive chemotherapy from consideration for hypo-fractionated treatment (Smith et al., 2009). There is only limited prospective data on the effect of chemotherapy on cumulative normal tissue toxicity after hypofractionated treatment as compared to conventional fractionation. As compared to Whelan et al. (2010) study where $10.9 \%$ patients received chemotherapy, in this series, approximately a third of patients received chemotherapy, balanced among the three treatment groups $(P=\mathrm{NS})$. There was no suggestion of increased toxicity among the patients who received chemotherapy and hypo-fractionation.

A limitation of the current report is the relatively short follow up, limited to 5 years. Whelan et al. $(2002,2010)$ demonstrated doubling of both skin (6 vs. $3 \%$ ) and subcutaneous tissue ( 8 vs. $4 \%)$ toxicity with longer follow up. Similarly, among the patients treated in the EORTC 22881-10882 "boost vs. no boost" trial a trend toward a dose-dependent development of fibrosis was seen at 10 year follow-up: severe fibrosis occurred in $3.3 \%$ after a boost of $10 \mathrm{~Gy}, 4.4 \%$ after $16 \mathrm{~Gy}$, and $14.4 \%$ after $26 \mathrm{~Gy}$, respectively (Bartelink et al., 2001; Poortmans et al., 2008). Yarnold et al. (2005) reported that patients who received a 14-Gy boost on the Royal Marsden Hospital/Gloucester Oncology Center (RMH/GOC) trial had a higher risk of breast induration and telangiectasia than those who did not receive a boost: however, there was no statistically significant difference between these groups in breast 
appearance, proportion of fair or poor cosmetic results, or risks of breast shrinkage, breast distortion, breast edema, arm swelling, or shoulder stiffness (Yarnold et al., 2005).

In this series, all patients were treated using a prone technique. All three treatments were regimens of $3 \mathrm{D}$ conformal radiation to the whole breast, with either an electron boost for the $6 \mathrm{wSB}$ schedule or an IMRT boost for the two accelerated schedules of CB to the tumor bed. Whether the prone approach permitted better conformality and dose homogeneity than standard supine set up remains to be established.

\section{REFERENCES}

Archambeau, J. O., Pezner, R., and Wasserman, T. (1995). Pathophysiology of irradiated skin and breast. Int. J. Radiat. Oncol. Biol. Phys. 31, 1171-1185.

Bartelink, H., Horiot, J. C., Poortmans, P., Struikmans, H., Van Den Bogaert, W., Barillot, I., Fourquet, A., Borger, J., Jager, J., Hoogenraad, W., Collette, L., and Pierart, M. (2001). Recurrence rates after treatment of breast cancer with standard radiotherapy with or without additional radiation. N. Engl. J. Med. 345, 1378-1387.

Bentzen, S. M., Agrawal, R. K., Aird, E. G., Barrett, J. M., Barrett-Lee, P. J., Bliss, J. M., Brown, J., Dewar, J. A., Dobbs, H. J., Haviland, J. S., Hoskin, P. J., Hopwood, P., Lawton, P. A., Magee, B. J., Mills, J., Morgan, D. A., Owen, J. R., Simmons, S., Sumo, G., Sydenham, M. A., Venables, K., and Yarnold, J. R. (2008). The UK Standardisation of Breast Radiotherapy (START) Trial A of radiotherapy hypofractionation for treatment of early breast cancer: a randomised trial. Lancet Oncol. 9, 331-341.

Croog, V. J., Wu, A. J., McCormick, B., and Beal, K. P. (2009). Accelerated whole breast irradiation with intensity-modulated radiotherapy to the prone breast. Int. J. Radiat. Oncol. Biol. Phys. 73, 88-93.

Darby, S., Mcgale, P., Correa, C., Taylor, C., Arriagada, R., Clarke, M., Cutter, D., Davies, C., Ewertz, M., Godwin, J., Gray, R., Pierce, L., Whelan, T., Wang, Y., and Peto, R. (2011). Effect of radiotherapy after breastconserving surgery on 10-year recurrence and 15-year breast cancer death: meta-analysis of individual patient data for 10,801 women in 17 randomised trials. Lancet 378, 1707-1716.

DeWyngaert, J. K., Jozsef, G., Mitchell, J., Rosenstein, B., and Formenti, S. C. (2007). Accelerated intensity- modulated radiotherapy to breast in Int. J. Radiat. Oncol. Biol. Phys. 68, 1251-1259.

Formenti, S. C., Gidea-Addeo, D., Goldberg, J. D., Roses, D. F., Guth, A., Rosenstein, B. S., and Dewyngaert, K. J. (2007). Phase I-II trial of prone accelerated intensity modulated radiation therapy to the breast to optimally spare normal tissue. $J$. Clin. Oncol. 25, 2236-2242.

Fowler, J. F. (1989). The linear-quadratic formula and progress in fractionated radiotherapy. Br. J. Radiol. 62, 679-694.

Freedman, G. M., Anderson, P. R., Goldstein, L. J., Ma, C. M., Li, J., Swaby, R. F., Litwin, S., Watkins-Bruner, M. (2007). Four-week course of radiation for breast cancer using hypofractionated intensity modulated radiation therapy with an incorporated boost. Int. J. Radiat. Oncol. Biol. Phys. 68, 347-353.

Haustermans, K., Fowler, J., Geboes, K., Christiaens, M. R., Lerut, A., and Van Der Schueren, E. (1998). Relationship between potential doubling time (Tpot), labeling index and duration of DNA synthesis in 60 esophageal and 35 breast tumors: is it worthwhile to measure Tpot? Radiother. Oncol. 46, 157-167.

Hoeller, U., Tribius, S., Kuhlmey, A., Grader, K., Fehlauer, F., and Alberti, W. (2003). Increasing the rate of late comparison of RTOG/EORTC and LENT/SOMA scores. Int. J. Radiat. Oncol. Biol. Phys. 55, 1013-1018.

Huppert, N., Jozsef, G., Dewyngaert, J. K., and Formenti, S. C. (2011). The role of a prone setup in breast radiation therapy. Front. Radiat. Ther. Oncol. 1, 1-8.

Jalali, R., Malde, R., Bhutani, R., Budrukkar, A., Badwe, R., and Sarin, R. (2008). Prospective evaluation of concomitant tumour bed boost with whole breast irradiation in patients with locally advanced breast cancer prone position: dosimetric results. D., Sigurdson, E. R., and Morrow, toxicity by changing the score? A

With a median follow up of 61 months, late toxicity was comparable among the three groups suggesting that the 3- or 5-week accelerated regimens utilizing $\mathrm{CB}$, designed on solid BED predictions, are well-tolerated, with comparable toxicities to those derived from standard 6 week fractionation.

\section{ACKNOWLEDGMENTS}

Supported in part by a grant from Varian Medical Systems "Prone Breast Radiotherapy: An NYU-Varian Synergy" TLC20110112-001A

undergoing breast-conserving therapy. Breast 17, 64-70.

James, M. L., Lehman, M., Hider, P. N., Jeffery, M., Hickey, B. E., and Francis, D. P. (2010). Fraction size in radiation treatment for breast conservation in early breast cancer. Cochrane Database Syst. Rev. CD003860.

Matthews, J. H., Meeker, B. E., and Chapman, J. D. (1989). Response of human tumor cell lines in vitro to fractionated irradiation. Int. J. Radiat. Oncol. Biol. Phys. 16, 133-138.

Owen, J. R., Ashton, A., Bliss, J. M., Homewood, J., Harper, C., Hanson, J., Haviland, J., Bentzen, S. M., and Yarnold, J. R. (2006). Effect of radiotherapy fraction size on tumour control in patients with early-stage breast cancer after local tumour excision: long-term results of a randomised trial. Lancet Oncol. 7, 467-471.

Poortmans, P. M., Collette, L., Bartelink, H., Struikmans, H., Van Den Bogaert, W. F., Fourquet, A., Jager, J. J., Hoogenraad, W., Muller, R. P., Dubois, J. B., Bolla, M., Van Der Hulst, M., Warlam-Rodenhuis, C. C. Pierart, M., and Horiot, J. C. (2008). The addition of a boost dose on the primary tumour bed after lumpectomy in breast conserving treatment for breast cancer. A summary of the results of EORTC 22881-10882 "boost versus no boost" trial. Cancer Radiother. 12, 565-570.

Rosenstein, B. S., Lymberis, S. C., and Formenti, S. C. (2004). Biologic comparison of partial breast irradiation protocols. Int. J. Radiat. Oncol. Biol. Phys. 60, 1393-1404.

Shafiq, J., Delaney, G., and Barton, M. B. (2007). An evidence-based estimation of local control and survival benefit of radiotherapy for breast cancer. Radiother. Oncol. 84, 11-17.

Smith, B. D., Arthur, D. W., Buchholz, T. A., Haffty, B. G., Hahn, C. A., Hardenbergh, P. H., Julian, T. B., Marks, L. B., Todor, D. A., Vicini, F. A., Whelan,
T. J., White, J., Wo, J. Y., and Harris, J. R. (2009). Accelerated partial breast irradiation consensus statement from the American Society for Radiation Oncology (ASTRO). Int. J. Radiat. Oncol. Biol. Phys. 74, 987-1001.

Stanton, P. D., Cooke, T. G., Forster, G., Smith, D., and Going, J. J. (1996). Cell kinetics in vivo of human breast cancer. Br. J. Surg. 83, 98-102.

Steel, G. G., Deacon, J. M., Duchesne, G. M., Horwich, A., Kelland, L. R., and Peacock, J. H. (1987) The dose-rate effect in human tumour cells. Radiother. Oncol. 9, 299-310.

Thames, H. D., Bentzen, S. M., Turesson, I., Overgaard, M., and Van Den Bogaert, W. (1990). Time-dose factors in radiotherapy: a review of the human data. Radiother. Oncol. 19, 219-235.

Travis, E. L., and Tucker, S. L. (1987). Isoeffect models and fractionated radiation therapy. Int. J. Radiat. Oncol. Biol. Phys. 13, 283-287.

Turesson, I., and Thames, H. D. (1989). Repair capacity and kinetics of human skin during fractionated radiotherapy: erythema, desquamation, and telangiectasia after 3 and 5 year's follow-up. Radiother. Oncol. 15, 169-188.

van der Laan, H. P., Dolsma, W. V., Maduro, J. H., Korevaar, E. W., Hollander, M., and Langendijk, J. A. (2007). Three-dimensional conformal simultaneously integrated boost technique for breast-conserving radiotherapy. Int. J. Radiat. Oncol. Biol. Phys. 68, 1018-1023.

Whelan, T., Mackenzie, R., Julian, J., Levine, M., Shelley, W., Grimard, L., Lada, B., Lukka, H., Perera, F., Fyles, A., Laukkanen, E., Gulavita, S., Benk, V., and Szechtman, B. (2002). Randomized trial of breast irradiation schedules after lumpectomy for women with lymph node-negative breast cancer. J. Natl. Cancer Inst. 94, 1143-1150. 
Whelan, T. J., Pignol, J. P., Levine, M. N., Julian, J. A., Mackenzie, R., Parpia, S., Shelley, W., Grimard, L., Bowen, J., Lukka, H., Perera, F., Fyles, A., Schneider, K., Gulavita, S., and Freeman, C. (2010). Long-term results of hypofractionated radiation therapy for breast cancer. N. Engl. J. Med. 362, 513-520.

Yamada, Y., Ackerman, I., Franssen, E., Mackenzie, R. G., and Thomas, G. (1999). Does the dose fractionation schedule influence local control of adjuvant radiotherapy for early stage breast cancer? Int.
J. Radiat. Oncol. Biol. Phys. 44, 99-104.

Yarnold, J., Ashton, A., Bliss, J., Homewood, J., Harper, C., Hanson, J., Haviland, J., Bentzen, S., and Owen, R. (2005). Fractionation sensitivity and dose response of late adverse effects in the breast after radiotherapy for early breast cancer: long-term results of a randomised trial. Radiother. Oncol. 75, 9-17.

Conflict of Interest Statement: The authors declare that the research was conducted in the absence of any commercial or financial relationships that could be construed as a potential conflict of interest.

Received: 07 March 2012; paper pending published: 15 April 2012; accepted: 16 April 2012; published online: 08 May 2012

Citation: Raza S, Lymberis SC, Ciervide $R$, Axelrod D, Fenton-Kerimian M, Magnolfi C, Rosenstein B, DeWyngaert JK and Formenti SC (2012) Comparison of acute and late toxicity of two regimens of 3- and 5-week concomitant boost prone IMRT to standard 6-week breast radiotherapy. Front. Oncol. 2:44. doi: 10.3389/fonc. 2012.00044

This article was submitted to Frontiers in Radiation Oncology, a specialty of Frontiers in Oncology.

Copyright $\odot 2012$ Raza, Lymberis, Ciervide, Axelrod, Fenton-Kerimian, Magnolf, Rosenstein, DeWyngaert and Formenti. This is an open-access article distributed under the terms of the Creative Commons Attribution Non Commercial License, which permits non-commercial use, distribution, and reproduction in other forums, provided the original authors and source are credited. 